\title{
Current Situation in the Struggle against Novel Coronavirus Infection (Covid-19)
}

\author{
Gulali Aktas* \\ Department of Internal Medicine, Abant Izzet Baysal University Hospital, Bolu, Turkey.
}

The lives of billions in the world have become to change by the end of 2019, almost two years ago, after novel coronavirus (Covid-19) infection emerged in Wuhan, China. Covid-19 caused about 33 millions of infection and 1000040 deaths worldwide within 10 months of the pandemic [1]. By December 18th of 2021, number of the infected subjects and deaths rose up to 274 million and 5364119, respectively [2].

Despite its devastating effect on human life, not even a single drug has shown significant enough efficacy against Covid-19 to change the course of the pandemic. However, some new agents and repurposed drugs were able to show efficacy to some extent. In the past 2 years, we have noticed that many Covid-19 cases have actually recovered without any treatment other than general measures. Indeed, most young and middle-aged people survive the disease mildly, yet the disease can be severe in people with advanced age and who have significant additional comorbidities. That's why, one of the most important things to do while waiting for the pandemic to end is to take and maintain measures to prevent the spread of Covid-19 in societies. Nevertheless, as the outbreak progressed, we began to consider Covid-19-related deaths as ordinary. Unfortunately, we also loosen the tight measures to control the disease.

We tried to develop new options in Covid-19 struggle in the past 2 years. As the pandemic enters its second year at the end of 2020, coronavirus vaccines have been added to our tools in struggling against Covid-19. Unfortunately, vaccines have not been able to reach communities in different parts of the world at the same time and to the same extent. This was one of the most important obstacles to the formation of herd immunity and the transformation of Covid-19 into a seasonal cold. Another problem in this regard was the frequent mutation feature of the virus [3]. Variants were followed the original Covid-19 virus, for instance, British variant, delta variant and most recent, but probably not the last, omicron variant. According to some researchers, the virus will continue to mutate as populations are delayed in vaccinating [4]. Omicron variant can infect about six times more people than delta variant [5]. On the other hand, more contagious and less virulent variant of the Covid-19 may end the millennium pandemic by causing a less serious disease like common cold

*Address correspondence to this author at the Department of Internal Medicine, Abant Izzet Baysal University Hospital, Bolu, Turkey. Email:draliaktas@yahoo.com and by replacing other Covid-19 variants due to its high transmission ability. Indeed, a recent study from South Africa which compared the characteristics of the patients infected with omicron, delta and previous variants and claimed that length of hospitalization, mortality rate and the rates of the subjects required oxygen supplementation, mechanical ventilation and treatment in intensive care were significantly lower in patients infected with omicron variant compared to the subjects with previous variants of Covid-19 [6]. However, further studies are needed to suggest their findings. Third barrier in reaching herd immunity could be the acts of anti-vaccine people. Not just themselves, they also caused indecision and reluctance to get vaccinated for a certain population.

In conclusion, we have to try to do our best in controlling Covid-19 outbreak. As the old saying goes, the destiny is in love with endeavor. Every person in the world, not just health workers, should play their role in the struggle against virus in sake of overcoming this issue. None should underestimate what he or she can do. We must remember that we are responsible for the struggling, not the victory.

\section{CONFLICT OF INTEREST}

Declared none.

\section{ACKNOWLEDGEMENTS}

I thank Ms. Maria Baig, Editorial Manager of National Journal of Health Sciences, for her Editorial Assistance throughout the manuscript completion.

\section{REFERENCES}

[1] Aktas G. A comprehensive review on rational and effective treatment strategies against an invisible enemy; SARS Cov-2 infection. Exp Biomed Res 2020; 3(4): 293-311.

[2] Covid-19 coronavirus pandemic. 2021; Available at: https://www.worldometers.info/coronavirus/. [Accessed on: 12/18/2021].

[3] Banerjee AK, Begum F, Ray U. Mutation hot spots in Spike protein of COVID-19. Preprints 2020; 2020: 2020040281.

[4] Rubin R. COVID-19 vaccines vs variants-determining how much immunity is enough. JAMA 2021; 325(13): 1241-3.

[5] Callaway E, Ledford H. How bad is Omicron? What scientists 
know so far. Nature 2021; 600(7888): 197-9.

[6] Maslo C, Friedland R, Toubkin M et al. Characteristics and outcomes of hospitalized patients in south africa during the
COVID-19 omicron wave compared with previous waves. JAMA 2021; [Online ahead of Print]. DOI: 10.1001/jama.2021.24868. 